\title{
Preface: Use of algae for monitoring rivers
}

\author{
Luc Ector • Daša Hlúbiková • Lucien Hoffmann
}

Published online: 22 June 2012

(C) Springer Science+Business Media B.V. 2012

In line with the previous symposia (Whitton et al., 1991; Whitton \& Rott, 1996; Prygiel et al., 1999; Ács et al., 2007), which were held in Germany (Düsseldorf, 1991), Austria (Innsbruck, 1995), France (Douai, 1997), United Kingdom (Durham, 2000), Poland (Cracow, 2003), and Hungary (Balatonfüred, 2006), the 7th International Symposium "Use of Algae for Monitoring Rivers", organized in Luxembourg (2009), focused on sharing experiences in the use of algae to monitor river water quality.

The Luxembourg symposium provided the opportunity to present new approaches and innovative methods in bioindication and use of various algal groups in water quality monitoring in different types of water bodies. The symposium also focused on uncovering the major gaps and uncertainties in existing methods or recent adaptations, as well as experiences with the application of these methods and intercalibration exercises.

During the symposium, invited speakers had the opportunity to present their research activities and results in plenary sessions. The main sessions focused

Guest editors: L. Ector, D. Hlúbiková \& L. Hoffmann / Proceedings of the 7th International Symposium "Use of Algae for Monitoring Rivers", Luxembourg, November 23-25, 2009

L. Ector $(\bowtie) \cdot$ D. Hlúbiková · L. Hoffmann

Department of Environment and Agro-biotechnologies (EVA), Public Research Centre-Gabriel Lippmann, 41 rue du Brill, 4422 Belvaux, Luxembourg

e-mail: ector@lippmann.lu on the following topics: algal ecology, toxicology (including cyanotoxins), river phytoplankton and phytobenthos monitoring, implementation of the Water Framework Directive (WFD), water quality monitoring in different countries. This 7th Symposium gathered about 80 participants and included 87 contributions ( 6 keynote conferences, 26 oral presentations and 55 poster presentations), submitted by researchers from 34 countries around the world: Australia, Austria, Belgium, Brazil, Canada, Czech Republic, Estonia, Ethiopia, Finland, France, Germany, Grand-duchy of Luxembourg, Hungary, India, Iran, Israel, Italy, Mexico, Mongolia, Morocco, New Zealand, Poland, Portugal, Russia, Serbia, Slovakia, South Africa, Spain, Sweden, Switzerland, The Netherlands, Turkey, United Kingdom, and the United States of America.

The 7th International Symposium "Use of Algae for Monitoring Rivers" was followed by two satellite workshops:

(1) The 1st European Workshop on Diatom Taxonomy with the main objective to give diatom specialists the opportunity to discuss and solve together taxonomical problems related to the identification of diatom taxa frequently found in water bodies (mainly rivers) and used for bioindication. Oral presentations combined with microscopy sessions focused on taxonomic problems related to the Achnanthidium minutissimum complex, a group of taxa with high relevance for bioindication studies in European waters. The 
results of this first workshop were published in the volumes 136-137 of the international journal Algological Studies (Ector, 2011).

(2) The European practical diatom intercalibration exercise/ring-test, organized by Maria Kahlert and Martyn Kelly, discussed during 2 days the preliminary results of a European-wide intercalibration exercise. The results of this ring-test are published in the present issue of Hydrobiologia (Kahlert et al., 2012).

The present Proceedings of the 7th International Symposium "Use of Algae for Monitoring Rivers" (Luxembourg, November 23-25, 2009) contains 25 contributions directly related to the 8 oral and the 3 poster sessions organized during the Symposium.

\section{Oral session 1: Use of algae or only diatoms?- Invasive species}

The invited speaker Brian Whitton gave a brief overview on how algae have been involved in monitoring nutrients in rivers over the past 20 years, followed by a critical assessment of the present methods (Whitton, 2012, this issue). Eugen Rott discussed the requirements for the successful use of benthic algae (including diatoms) for monitoring rivers and the problems related to standardization, taxonomic instability and regional calibration, with reference to progress in Austria and Switzerland. The development and evaluation of benthic algal bioassessment protocols for use in Ontario rivers were described by Natasa Zugic-Drakulic. Concerning the invasive species, Philippe Gerbeaux gave an update on recent and future research on Didymosphenia geminata in New Zealand and Marina Aboal presented the ultrastructure and function of the very large branched stalks of this diatom based on the study of two populations, one from a stream in northern England and another one from a river on Vancouver Island, Canada (Aboal et al., 2012, this issue).

\section{Oral session 2: Algal ecology and molecular approach}

The invited speaker Jan Stevenson made a presentation on the application of a suite of algal indicators for setting management targets, assessing condition, and diagnosing stressors (Stevenson et al., 2012, this issue). Elisabet Tornés presented an interesting talk addressing the question: Is the biological classification of benthic diatom communities concordant with ecoregions? (Tornés et al., 2012, this issue). Virginia Loza developed a novel and effective technology for monitoring cyanobacterial diversity from river biofilms using molecular fingerprinting and microscopy methods for assessing water quality. Marco Berzano proposed a new molecular approach for the identification of freshwater diatoms for water quality assessment (Berzano et al., 2012, this issue).

\section{Oral session 3: Toxicology, pesticides, and heavy metals}

Francisca Fernández-Piñas evaluated the toxicological interaction of complex mixtures of contaminants in aqueous samples using bioluminescent cyanobacteria. Lucyna Wlodarczyk explained a simple and timesaving fluorometric method that can be applied to monitor the abundance of cyanobacteria in drinking water sources and recreational water bodies, relying on a fluorescence-based online analysis of cyanobacterial chlorophyll $a$ and phycocyanin (Wlodarczyk et al., 2012, this issue). On the basis of an experimental study on pollution-induced community tolerance (PICT), Ahmed Tlili analyzed the impact of chronic and acute pesticide contamination scenarios on phototrophic periphyton communities. Bohuslav Uher presented a study on the effect of mining water on phytobenthic assemblages in a running water system.

\section{Oral session 4: Biofilms and choice of substrate}

The invited speaker Sergi Sabater demonstrated how the autotrophic biofilms can be used as early warning systems in multistress situations. Soizic Morin explained the patterns of biofilm formation in two streams under different hydrological regimes (Artigas et al., 2012, this issue). Agata Wojtal talked about the influence of substrates in diatom-based water quality assessment in Polish limestone springs (Wojtal \& Sobczyk, 2012, this issue) and Marco Cantonati presented the use of epilithic and epiphytic (on the Rhodophyte Bangia atropurpurea) diatoms to assess 
the environmental quality of the shores of the Italian lake Garda.

\section{Oral session 5: New methodologies and intercalibration exercise}

Recently, efforts have focused on testing and adapting European-based diatom indices for South Africa. In this context, Jonathan Taylor explained the development of a new diatom index for South African rivers and streams. Maria Kahlert presented the results of the first European practical diatom intercalibration exercise/ring-test (Kahlert et al., 2012, this issue).

\section{Oral session 6: River phytoplankton and phytobenthos}

The European Union WFD prescribes the use of algae for water quality assessment and the invited speakers Éva Ács and Keve Kiss explained the improvement of the ecological water qualification system of rivers based on first results of the Hungarian phytobenthos and phytoplankton monitoring (Várbíró et al., 2012, this issue). Daša Hlúbiková tested both phytobenthosand phytoplankton-based assessment methods of the ecological status of rivers in Slovakia. Elena Mitrofanova demonstrated how to use the phytoplankton as indicator of the water quality of the Ob River near the large industrial center of Barnaul in Russia. Joanna Picinska-Fałtynowicz showed that reference communities of benthic diatom communities in Polish rivers are composed of taxa indicating low trophic and/or saprobic status.

\section{Oral session 7: WFD implementation}

The invited speaker Petr Marvan explained how in the framework of the WFD the water quality monitoring based on the traditional concept of trophic and saprobic water quality classification is replaced by objective ecological status metrics for human deterioration of water quality from a natural state. Ingrid Jüttner used the diatoms as quality indicators for the newly formed urban lake Cardiff Bay and catchments of the inflowing rivers Taff and Ely (Jüttner et al.,
2012, this issue). Satu Maaria Karjalainen compared different approaches based on diatoms for the classification of the ecological state of Finnish rivers. In the Water Framework Directive context, Maria Elena Beltrami defined the diatom assemblages of South Tyrol watercourses (Bozen province, Northern Italy) and gave an overview of their biological quality assessed with the application of different diatom indices (Beltrami et al., 2012, this issue).

\section{Oral session 8: Taxonomy and monitoring in different countries}

The invited speaker Horst Lange-Bertalot reported on his work on the diatom species of the genus Eunotia, their distribution and autecology in waters of Europe and North America. Bart Van de Vijver addressed about the curse of taxonomic accuracy by wondering whether we did open Pandora's box because the current application of a narrower species concept, in combination with new techniques such as molecular analysis and better microscopical instruments, have revealed the presence of far more diatom taxa than previously accepted. In SW Spain (Guadiana River), Gemma Urrea-Clos could identify reference benthic diatom communities in an agricultural watershed (Urrea-Clos \& Sabater, 2012, this issue). Finally, Raffaella Zorza presented the first results on the use of diatoms to assess water bodies in Friuli Venezia Giulia, NE Italy and Jacob John illustrated the main achievements and challenges concerning the use of algae in monitoring rivers in Australia.

Moreover, several papers based on posters presented during the 7th International Symposium are included in this issue of Hydrobiologia (Almeida \& Feio, 2012; Blanco et al., 2012; Della Bella et al., 2012; Elias et al., 2012; Falasco et al., 2012; Kelly \& Ector, 2012; Novais et al., 2012; Proia et al., 2012; Romanov \& Kirillov, 2012; Rusanov et al., 2012; Sorokovikova et al., 2012; Triest et al., 2012).

The financial support provided by the FNR (Fonds National de la Recherche, Luxembourg) was essential for organizing the 7th International Symposium "Use of Algae for Monitoring Rivers" in Luxembourg and allowed the invitation of several $\mathrm{PhD}$ students and also prominent scientists in the field of the use of algae for monitoring rivers. 


\section{References}

Aboal, M., S. Marco, E. Cháves, I. Mulero \& A. García-Ayala, 2012. Ultrastructure and function of stalks of the diatom Didymosphenia geminata. Hydrobiologia. doi:10.1007/ s10750-012-1193-y.

Ács, É., K. T. Kiss \& J. Padisák (eds), 2007. Proceedings of 6th International Symposium on Use of Algae for Monitoring Rivers, Hungary, Balatonfüred, 12-16 Sept 2006. Archiv für Hydrobiologie Supplement 161, Large Rivers 17: 265-549.

Almeida, S. F. P. \& M. J. Feio, 2012. DIATMOD: diatom predictive model for quality assessment of Portuguese running waters. Hydrobiologia. doi:10.1007/s10750-012-1110-4.

Artigas, J., K. Fund, S. Kirchen, S. Morin, U. Obst, A. M. Romaní, S. Sabater \& T. Schwartz, 2012. Patterns of biofilm formation in two streams from different bioclimatic regions: analysis of microbial community structure and metabolism. Hydrobiologia. doi:10.1007/s10750-012-1111-3.

Beltrami, M. E., F. Ciutti, C. Cappelletti, B. Lösch, R. Alber \& L. Ector, 2012. Diatoms from Alto Adige/Südtirol (Northern Italy): characterization of assemblages and their application for biological quality assessment in the context of the Water Framework Directive. Hydrobiologia. doi: 10.1007/s10750-012-1194-x.

Berzano, M., S. Marcheggiani, S. Rombini \& R. Spurio, 2012. The application of oligonucleotide probes and microarrays for the identification of freshwater diatoms. Hydrobiologia. doi:10.1007/s10750-012-1112-2.

Blanco, S., C. Cejudo-Figueiras, L. Tudesque, E. Bécares, L. Hoffmann \& L. Ector, 2012. Are diatom diversity indices reliable monitoring metrics? Hydrobiologia. doi: 10.1007/s10750-012-1113-1.

Della Bella, V., G. Pace, M. Barile, A. Zedde, C. Puccinelli, S. Ciadamidaro, P. P. Danieli, P. Andreani, F. A. Aulicino, C. Belfiore \& L. Mancini, 2012. Benthic diatom assemblages and their response to human stress in small-sized volcanicsiliceous streams of central Italy (Mediterranean ecoregion). Hydrobiologia. doi:10.1007/s10750-012-1195-9.

Ector, L., 2011. 1st European Workshop on Diatom Taxonomy (1st EWDT). Algological Studies 136-137: 1-4.

Elias, C. L., N. Vieira, M. J. Feio \& S. F. P. Almeida, 2012. Can season interfere with diatom ecological quality assessment? Hydrobiologia. doi:10.1007/s10750-012-1196-8.

Falasco, E., L. Ector, E. Ciaccio, L. Hoffmann \& F. Bona, 2012. Alpine freshwater ecosystems in a protected area: a source of diatom diversity. Hydrobiologia. doi:10.1007/s10750012-1114-0.

Jüttner, I., P. J. Chimonides \& S. J. Ormerod, 2012. Developing a diatom monitoring network in an urban river-basin: initial assessment and site selection. Hydrobiologia. doi:10.1007/ s10750-012-1123-z.

Kahlert, M., M. Kelly, R.-L. Albert, S. F. P. Almeida, T. Bešta, S. Blanco, M. Coste, L. Denys, L. Ector, M. Fránková, D. Hlúbiková, P. Ivanov, B. Kennedy, P. Marvan, A. Mertens, J. Miettinen, J. Picinska-Fałtynowicz, J. Rosebery, E. Tornés, S. Vilbaste \& A. Vogel, 2012. Identification versus counting protocols as sources of uncertainty in diatombased ecological status assessments. Hydrobiologia. doi: 10.1007/s10750-012-1115-z.
Kelly, M. G. \& L. Ector, 2012. Effect of streamlining taxa lists on diatom-based indices: implications for intercalibrating ecological status. Hydrobiologia. doi:10.1007/s10750012-1116-y.

Novais, M. H., S. Blanco, C. Delgado, M. Morais, L. Hoffmann \& L. Ector, 2012. Ecological assessment of Portuguese reservoirs based on littoral epilithic diatoms. Hydrobiologia. doi:10.1007/s10750-012-1197-7.

Proia, L., A. M. Romaní \& S. Sabater, 2012. Nutrients and light effects on stream biofilms: a combined assessment with CLSM, structural and functional parameters. Hydrobiologia. doi:10.1007/s10750-012-1117-x.

Prygiel, J., B. A. Whitton \& J. Bukowska (eds), 1999. Use of Algae for Monitoring Rivers III. Agence de l'Eau ArtoisPicardie, Douai: 271 pp.

Romanov, R. E. \& V. V. Kirillov, 2012. Analysis of the seasonal dynamics of river phytoplankton based on succession rate indices for key event identification. Hydrobiologia. doi: 10.1007/s10750-012-1198-6.

Rusanov, A. G., E. V. Stanislavskaya \& É. Ács, 2012. Periphytic algal assemblages along environmental gradients in the rivers of the Lake Ladoga basin, Northwestern Russia: implication for the water quality assessment. Hydrobiologia. doi:10.1007/s10750-012-1199-5.

Sorokovikova, L. M., G. I. Popovskaya, O. I. Belykh, I. V. Tomberg, S. Yu. Maksimenko, N. V. Bashenkhaeva, V. G. Ivanov \& T. I. Zemskaya, 2012. Plankton composition and water chemistry in the mixing zone of the Selenga River with Lake Baikal. Hydrobiologia. doi:10.1007/ s10750-012-1200-3.

Stevenson, R. J., B. J. Bennett, D. N. Jordan \& R. D. French, 2012. Phosphorus regulates stream injury by filamentous green algae, $\mathrm{DO}$, and $\mathrm{pH}$ with thresholds in responses. Hydrobiologia. doi:10.1007/s10750-012-1118-9.

Tornés, E., M. Leira \& S. Sabater, 2012. Is the biological classification of benthic diatom communities concordant with ecotypes? Hydrobiologia. doi:10.1007/s10750-012-1119-8.

Triest, L., H. Lung'ayia, G. Ndiritu \& A. Beyene, 2012. Epilithic diatoms as indicators in tropical African rivers (Lake Victoria catchment). Hydrobiologia. doi:10.1007/s10750012-1201-2.

Urrea-Clos, G. \& S. Sabater, 2012. Identifying reference benthic diatom communities in an agricultural watershed (Guadiana River, SW Spain). Hydrobiologia. doi:10.1007/ s10750-012-1202-1.

Várbíró, G., G. Borics, B. Csányi, G. Fehér, I. Grigorszky, K. T. Kiss, A. Tóth \& É. Ács, 2012. Improvement of the ecological water qualification system of rivers based on the first results of the Hungarian phytobenthos surveillance monitoring. Hydrobiologia. doi:10.1007/s10750-012-1120-2.

Whitton, B. A., 2012. Changing approaches to monitoring during the period of the 'Use of Algae for Monitoring Rivers' symposia. Hydrobiologia. doi:10.1007/s10750012-1121-1.

Whitton, B. A. \& E. Rott (eds), 1996. Use of Algae for Monitoring Rivers II. Institut für Botanik, Universität Innsbruck, Innsbruck: $196 \mathrm{pp}$.

Whitton, B. A., E. Rott \& G. Friedrich (eds), 1991. Use of Algae for Monitoring Rivers. Institut für Botanik, Universität Innsbruck, Innsbruck: 193 pp. 
Wlodarczyk, L. M., C. Moldaenke \& L. Fiedor, 2012. Fluorescence as a probe for physiological integrity of freshwater cyanobacteria. Hydrobiologia. doi:10.1007/s10750012-1122-0.

Wojtal, A. Z. \& Ł. Sobczyk, 2012. The influence of substrates and physicochemical factors on the composition of diatom assemblages in karst springs and their applicability in water-quality assessment. Hydrobiologia. doi:10.1007/ s10750-012-1203-0. 